\title{
Resolution of multiple sheet-type structures in self-potential measurement
}

\author{
Arkoprovo Biswas and Shashi Prakash Sharma* \\ Department of Geology and Geophysics, Indian Institute of Technology, Kharagpur, West Bengal 721 302, India. \\ ${ }^{*}$ Corresponding author. e-mail: spsharma@gg.iitkgp.ernet.in
}

The resolution of self-potential anomalies due to closely spaced multiple sheet-like bodies by the potential difference and potential gradient is studied in this paper. Self-potential anomalies due to several synthetic models were inverted through a very fast simulated annealing (VFSA) global optimization. Increase in depth to the top, polarization constant and depth extent of the body decreases resolution at a particular target separation. It has been observed that depth to the top and separation between two targets play an important role in the resolution. Vertical sheets at equal depth can be resolved in the potential difference measurement only if they are separated by at least four times their depth, while they can be resolved in the gradient method, if they are separated by twice the depth. Resolution using potential difference becomes more difficult for dipping sheets, although the potential gradient method can resolve them efficiently. Efficacy of potential gradient data in the inversion is demonstrated in the study using synthetic data as well as field measurement from South Purulia Shear Zone related with uranium investigation.

\section{Introduction}

The Self-Potential (SP) method is a passive source method that employs the measurement of naturally occurring potential difference due to electrochemical, electro-kinetic and thermoelectric fields of the Earth's surface (Telford et al. 1990). A majority of the targets explored by SP measurements are in the form of dipping sheets, the inversion of whose anomalies was adequately studied (e.g., Sundararajan et al. 1998; Mendonca 2008; Ramazi et al. 2009; Sharma and Biswas 2013). Field data are often associated with multiple sheet-type structures and isolated structures that rarely occur in nature. The self-potential anomalies generated by multiple targets are broader and may provide misleading interpretation, when dealt with the tools applicable for an isolated sheet.
Usually SP measurements are carried out in two different ways in the field. In Potential Difference $(\mathrm{PD})$ measurement, one electrode is fixed at the base station and the other electrode moves at a regular interval, whereas in Potential Gradient (PG) measurement, both electrodes move at a fixed interval. Even though it is obvious that potential gradient measurement gives better lateral resolution than potential difference measurement, it is rarely used in the quantitative interpretation. Multiple sheet-type closely spaced structures are often encountered (Monteiro Santos et al. 2002) in the field and their resolution is quite important to delineate the actual model parameters of the subsurface structures. It is rather difficult to determine the actual model parameters when the structures are dipping and are oriented in different directions. This kind of resolution and ambiguity study is missing in the literature.

Keywords. Self-potential; potential difference; potential gradient; resolution; multiple structures; global optimization. 
In the present study, the role of various parameters such as depth to the top, depth extent, dip, polarization constant, and separation between structures is studied on PD and PG measurements to resolve closely spaced multiple sheet-type structures. Forward modelling is performed by varying various parameters and $\mathrm{PD}$ and $\mathrm{PG}$ anomalies are analysed. A very fast simulated annealing (VFSA) global optimization is also performed to study the efficacy of both measurements in depicting the actual structure. The method has been tested for noise-free synthetic data, noisy data and field example from Beldih mine, South Purulia Shear Zone related with uranium investigation to show the efficacy of the approach.

\section{Forward formulation}

The general equation of SP anomaly $V\left(x_{i}\right)$ at any point $\mathrm{P}$ on a profile perpendicular to the strike of a 2-D inclined sheet (Murthy and Haricharan 1985; Sundararajan et al. 1998) is written as:

$$
V\left(x_{i}\right)=k \ln \left[\frac{\left\{\left(x_{i}-x_{0}\right)-a \cos \alpha\right\}^{2}+(h-a \sin \alpha)^{2}}{\left\{\left(x_{i}-x_{0}\right)+a \cos \alpha\right\}^{2}+(h+a \sin \alpha)^{2}}\right] \text {. }
$$

In equation (1a), electric dipole density or polarization constant $k=I \rho / 2 \pi$ ( $I$ is the current density of the medium and $\rho$ is the resistivity of the sheet), $x$ coordinate of the centre of the sheet $x_{0}$, depth of the centre of the sheet $h$, half-width of the sheet $a$ and inclination angle $\alpha$. The numerator and denominator of equation (1a) is nothing but the square of the distance of the top $\left(r_{1}\right)$ and bottom $\left(r_{2}\right)$ edge of the sheet from the observation point.

$$
V\left(x_{i}\right)=k \ln \left(\frac{r_{1}^{2}}{r_{2}^{2}}\right) .
$$

It is convenient to express equation (1a) in terms of the coordinates of the upper end $\left(x_{1}, z_{1}\right)$ and lower end $\left(x_{2}, z_{2}\right)$ of the sheet to model multiple sheet structures (figure 1).

$$
V\left(x_{i}\right)=k \ln \left(\frac{\left(x_{i}-x_{1}\right)^{2}+z_{1}^{2}}{\left(x_{i}-x_{2}\right)^{2}+z_{2}^{2}}\right) .
$$

In the present study, model parameters of equation (1c) have been used. The unit of $k$ is $\mathrm{mV}$ (milli volts) and $x$ and $z$ coordinates are in meters $(\mathrm{m})$.

The Potential Gradient ' $G$ ' can be computed numerically as:

$$
G\left(x_{i}+d x_{i}\right)=\frac{\left[V\left(x_{i+1}\right)-V\left(x_{i}\right)\right]}{\left(x_{i+1}-x_{i}\right)},
$$

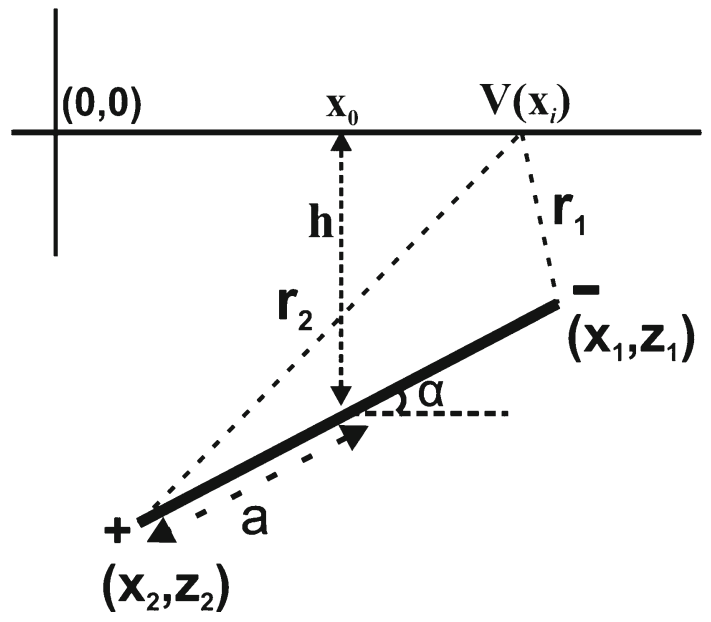

Figure 1. Inclined sheet geometry of infinite horizontal extent.

where $d x_{i}=\left(x_{i+1}-x_{i}\right) / 2, x_{i}$ denotes the location potential difference measurement $V\left(x_{i}\right)$ and $x_{i}+d x_{i}$ notes the location of potential gradient measurement.

For multiple sheet-type structures, the equation for potential difference can be written as:

$$
V\left(x_{i}\right)=\sum_{j=1}^{M} V_{j}\left(x_{i}\right),
$$

where $V_{j}\left(x_{i}\right)$ is the potential difference at $x_{i}$ location for $j$ th body and $M$ is the number of bodies.

\section{Very fast simulated annealing (VFSA) global optimization}

Global optimization methods are based on different principles such as Boltzmann's law of statistical mechanics to the minimum energy state (simulated annealing), biological evolution (genetic algorithm and neural network), natural behaviour of an individual or a group follow optimum path (particle swarm optimizations). These methods overcome various limitations of linearized inversions (Sen and Stoffa 1995). In the present study, a variant of simulated annealing (SA) which is known as very fast simulated annealing (VFSA) is used for the optimization of model parameters of a sheet-type structure. The VFSA is more efficient than conventional SA approach in terms of less CPU time, memory and resolution (Ingber and Rosen 1992). The approach has been used by various scientists for interpretation of different geophysical data (Zhao et al. 1996; Sharma and Kaikkonen 1998, 1999; Bhattacharya et al. 2003; Pei et al. 2009; Srivastava and Sen 2009; Li et al. 2011; Sharma 2012; Sharma and Biswas 2013). The efficacy of VFSA is such 
that it is widely applied in other non-geophysical problems as well. The VFSA process is discussed in detail in various literatures mentioned above. Further, different geophysical problems require different types of objective functions. We find the following misfit error $(\varphi)$ between the observed and model response suitable for SP data interpretation.

$$
\varphi=\frac{1}{N} \sum_{i=1}^{N}\left(\frac{d_{i}^{0}-d_{i}^{c}}{\left|d_{i}^{0}\right|+\left(d_{\max }^{0}-d_{\min }^{0}\right) / 2}\right)^{2},
$$

where $N$ is the number of data point, $d_{i}^{0}$ and $d_{i}^{c}$ are the $i$ th observed and model responses (both for $\mathrm{PD}$ and $\mathrm{PG}), d_{\max }^{0}$ and $d_{\min }^{0}$ are the maximum and minimum values of observed response.

The misfit like equation (4) is minimized in every geophysical optimization and it is very small for a perfectly fitting model. As simulated annealing, global optimization uses the concept of energy of molecules with temperature in thermodynamical system, misfit in geophysical optimization is correlated with energy in thermodynamical system. As energy is related with temperature in thermodynamical system, misfit in geophysical optimization is equivalent to temperature. At very low temperature, molecules of thermodynamical systems are in the state of the lowest energy in a similar way as we get the lowest misfit for the best fitted model. For brevity, we do not describe the complete VFSA process here and refer Sharma and Biswas (2013) which deals with the ambiguity analysis in the interpretation of self-potential data.

\section{Global model and uncertainty analysis}

To obtain a best fitting solution, computations are performed at 2000 different temperature levels with 50 moves at each temperature level. The VFSA procedure is repeated 10 times and the 10 best fitting solutions are obtained. $10^{6}$ models and their misfit are stored in memory where misfit varies from $1-10^{-8}$. Out of these models, models whose misfit is higher than the defined threshold (0.0001 for noise-free synthetic data and 0.02 for noisy and field data) value are discarded. Therefore, only models that fit the observed response up to a certain degree are selected for statistical analysis.

The histogram of models with misfit lower than the pre-defined threshold shows Gaussian distribution. Therefore, Gaussian Probability Density Function (PDF) is computed. The Gaussian probability density function $f_{y}\left(y, \mu, \sigma^{2}\right)$ of a variable $y$ with $\mu$ and $\sigma$ as the mean and standard deviation, respectively, is given by

$$
f\left(y, \mu, \sigma^{2}\right)=\frac{1}{\sigma \sqrt{2 \pi}} e^{-\frac{1}{2}\left(\frac{y-\mu}{\sigma}\right)^{2}} .
$$

The PDF for all selected good fitting models is computed using equation (5) and subsequently the maximum value of PDF for each model parameter is picked up. A $60.65 \%$ limit (one standard deviation) is set for each parameter for the selection of good models lying in the high $\mathrm{PDF}$ region of the model space for the computation of the mean model. Any model in which any parameter lies outside of one standard deviation is also eliminated. Thus models in the high probability region in the multi-dimensional model space are selected for computation of the mean model. The mean model, covariance and correlation matrices (equations 6, 7 and 8, respectively) are computed using the formulation given by Tarantola (1987).

$$
\bar{P}_{i}=\frac{1}{N M} \sum_{n=1}^{N M} P_{i, n} .
$$

In the above equation, $N M$ is the number of models in a higher PDF region of the model space.

$$
\begin{gathered}
\operatorname{cov} P(i, j)=\frac{1}{N M} \sum_{n=1}^{N M}\left(P_{i, n}-\bar{P}_{i}\right)\left(P_{j, n}-\bar{P}_{j}\right), \\
\operatorname{cor} P(i, j)=\frac{\operatorname{cov} P(i, j)}{\sqrt{\operatorname{cov} P(i, i) \operatorname{cov} P(j, j)}} .
\end{gathered}
$$

In equations (6-8), $i$ and $j$ vary from 1 to $N P$ (the number of model parameters). Uncertainties in the mean model parameters are estimated from the square roots of the diagonal elements of the covariance matrix (equation 7 ). The correlation matrix (equation 8) computed using best-fitting solutions depicts the interdependence of each parameter pair.

\section{Results}

\subsection{Synthetic example}

Initially a model comprising of three vertical sheettype targets (figure 2 and table 1 ) is considered. All three targets have the same geometry but they are separated by a $50 \mathrm{~m}$ lateral distance. The depth to the top of each body is $25 \mathrm{~m}$ and $100 \mathrm{~m}$ length in vertical direction. The polarization constant $(k)$ for all three targets is $300 \mathrm{mV}$. The forward responses for $\mathrm{PD}$ and $\mathrm{PG}$ are computed for this basic model. Subsequently, each model parameter depth 


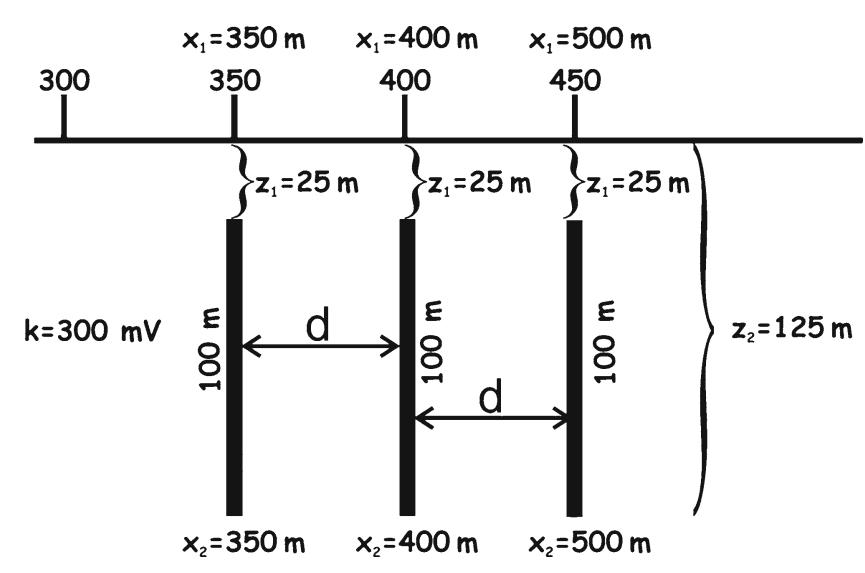

Figure 2. Sheet geometry for multiple closely spaced structures.

Table 1. Parameters of the basic model.

\begin{tabular}{lccc}
\hline Parameters & Target 1 & Target 2 & Target 3 \\
\hline$k(\mathrm{mV})$ & 300 & 300 & 300 \\
$x_{1}(\mathrm{~m})$ & 350 & 400 & 450 \\
$z_{1}(\mathrm{~m})$ & 25 & $\mathbf{2 5}$ & 25 \\
$x_{2}(\mathrm{~m})$ & 350 & 400 & 450 \\
$z_{2}(\mathrm{~m})$ & 125 & 125 & $\mathbf{1 2 5}$ \\
\hline
\end{tabular}

to the top $(z$, depth extent, $\operatorname{dip}(\alpha)$, polarization constant $(k)$ and separation between structures are varied and compared. Next we added 20\% uniformly random noise (i.e., multiplied by a random draw between 1 and 1.20) and 20\% Gaussian noise (i.e., multiplied by a Gaussian random value with mean 1 and standard deviation 0.2 ) to the noise free synthetic data and plotted the responses. The $x_{2}, z_{2}$ coordinates of the bottom edge of the target is kept at a distance that the target makes the desired angle.

\subsubsection{Effect of variation in depth to the top $\left(z_{1}\right)$}

First forward response for the basic model shown in table 1 is computed and shown in figure 3(a). From figure 3(a), we could see that multiple targets are not resolved in potential difference anomaly; however, they are resolved in potential gradient anomaly. Subsequently we reduced the depth to the top to $15 \mathrm{~m}$ from $25 \mathrm{~m}$ and computed the anomaly. Though the magnitude of PD anomaly has increased, it still cannot reveal three structures whereas potential gradient anomaly yields very clear information and gives out 3 targets.

Since field data are always associated with different kinds of noises, effect of random and Gaussian noise has also been analysed. It is emphasized that potential difference is measured between two electrodes whose distance continuously increases. Any noise source located at a particular point between the two electrodes will affect all dataset measured beyond that noisy source along a profile. In other words, noise gets cumulative in potential difference measurement. However, that particular noise source will affect PG measurement only at that particular location.

Figure 3(b and c) shows the anomaly with $20 \%$ random noise and Gaussian noise data. As mentioned above, $\mathrm{PD}$ data looks noisier than $\mathrm{PG}$ data for the same amount of random and Gaussian noise. Therefore, PG measurement is more reliable to depict multiple structures in noisy conditions rather than $\mathrm{PD}$ measurements.

Comparison of potential gradient anomaly suggests that when depth to the top is $25 \mathrm{~m}$ for the given target separation of $50 \mathrm{~m}$, then potential gradient anomaly just resolves the structure (figure 3a). When the target moves to a deeper depth then PG anomaly would also not be able to resolve the structure.

\subsubsection{Effect of variation in depth extent $\left(z_{2}\right)$}

To study the effect of variation of depth extent on the resolution, the coordinate $z_{2}$ in table 1 is changed to $250 \mathrm{~m}$ by keeping other parameters same. The forward responses are computed and compared with the responses of models shown in table 1 (figure 4a). The magnitude of $\mathrm{PD}$ anomaly increases but $\mathrm{PG}$ anomaly remains in the similar magnitude. Further, increasing depth extent has no effect in lateral resolution. Again, we have plotted the response after addition of noise to the data (figure $4 \mathrm{~b}$ and $\mathrm{c}$ ). The noisy data shows the same features as observed in noise-free data.

\subsubsection{Effect of variation in dip}

In this case, we have varied the dip angle $\left(45^{\circ}\right.$, $60^{\circ}$ and $90^{\circ}$ ) of the sheet and computed the forward response to study whether PD and PG can resolve the structures. To make the dipping structure, the coordinate $x_{2}$ and $z_{2}$ of targets in table 1 are changed such that the target makes $45^{\circ}$ and $60^{\circ}$ from horizontal. The results of varying dip with the initial vertical structures are shown in figure 5(a). As expected, asymmetric responses are observed for dipping structures, which is clearly seen in PD anomalies. Regarding resolution of PD anomaly, it will further deteriorate for dipping targets and also when the data is associated with noise (figure 5b and c). Further, PG responses also show poor performance regarding lateral resolution for dipping targets. In PG responses small differences that are seen may be lost if noise is present in the data (figure $5 \mathrm{~b}$ and $\mathrm{c}$ ). 

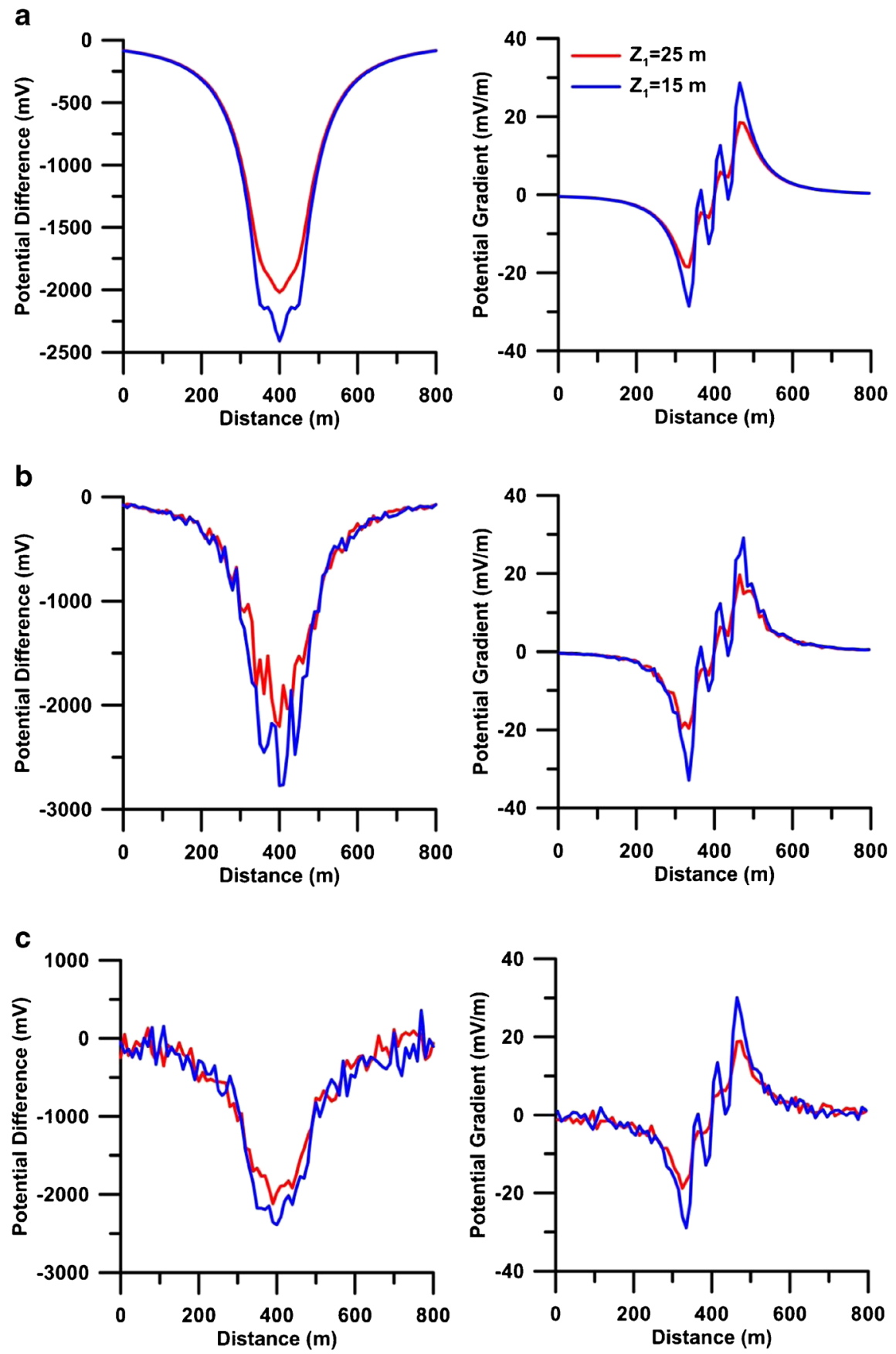

Figure 3. Potential difference and potential gradient anomaly with varying $z_{1}$ : (a) noise-free data; (b) $20 \%$ random noise data; and (c) $20 \%$ Gaussian noise data.

\subsubsection{Effect of variation in polarization constant ( $k$ )}

To study the effect of polarization constant on the resolution, we increased it from $300 \mathrm{mV}$ (as shown in table 1) to $500 \mathrm{mV}$. The forward responses are computed and compared (figure 6a). The PD shows a single body like structure on increasing polarization constant $(k)$ for multiple structures. This suggests that closely spaced multiple structures cannot be resolved with higher $k$ and $\mathrm{PD}$ cannot resolve all the bodies. Even if there are multiple structures, measuring PD is not suitable for any interpretation of vertical or dipping structures. It combines all the responses for each structure and gives a higher polarization constant $(k)$ value. Moreover, presence of noise in the data severely affects the original anomaly (figure $6 \mathrm{~b}$ and c). However, PG can resolve the multiple bodies equally well with different polarization constant $(k)$ values as this gives the cumulative sum of all polarization constants $(k)$ for each sheet-type structure. Also, the PG data can resolve the structure in the presence of noise (figure $6 \mathrm{~b}$ and $\mathrm{c}$ ). 

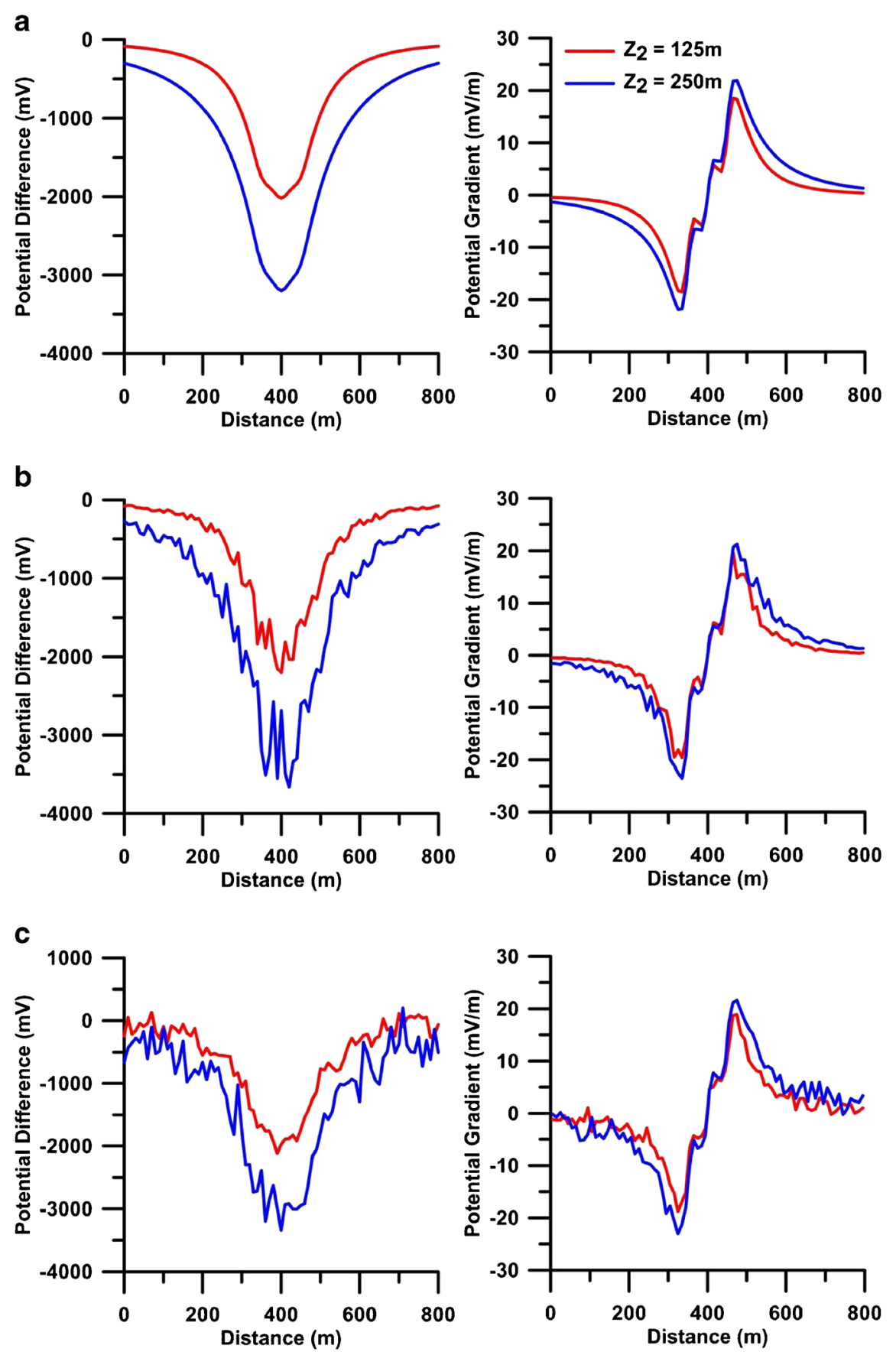

Figure 4. Potential difference and potential gradient anomaly with varying $z_{2}$ : (a) noise-free data; (b) $20 \%$ random noise data; and (c) $20 \%$ Gaussian noise data.

It is important to highlight that SP anomaly reduces to background value rapidly for a small $k$ value in comparison to large $k$ (figure 6a). If multiple targets are located at small distances then resolution of target having small $k$ will be better than the target with large $k$.

\subsubsection{Effect of variation in separation (d)}

In this example, the separation between sheets varied as 50,75 and $100 \mathrm{~m}$ and forward response is computed. To do this, in table 1 we kept $x_{1}$ as 350,400 and $450 \mathrm{~m}$ for $50 \mathrm{~m}$ separation, 325 , 400 , and $475 \mathrm{~m}$ for $75 \mathrm{~m}$ separation, and 300 , 400 , and $500 \mathrm{~m}$ for $100 \mathrm{~m}$ separation, respectively. The corresponding forward responses are shown in figure $7(\mathrm{a})$. Here, we can see that PG can resolve multiple bodies at different separations. It can also resolve the exact location of the body very precisely even though the data is associated with noise (figure $7 \mathrm{~b}$ and $\mathrm{c}$ ). However, to resolve multiple bodies with $\mathrm{PD}$, it needs four times the depth from 

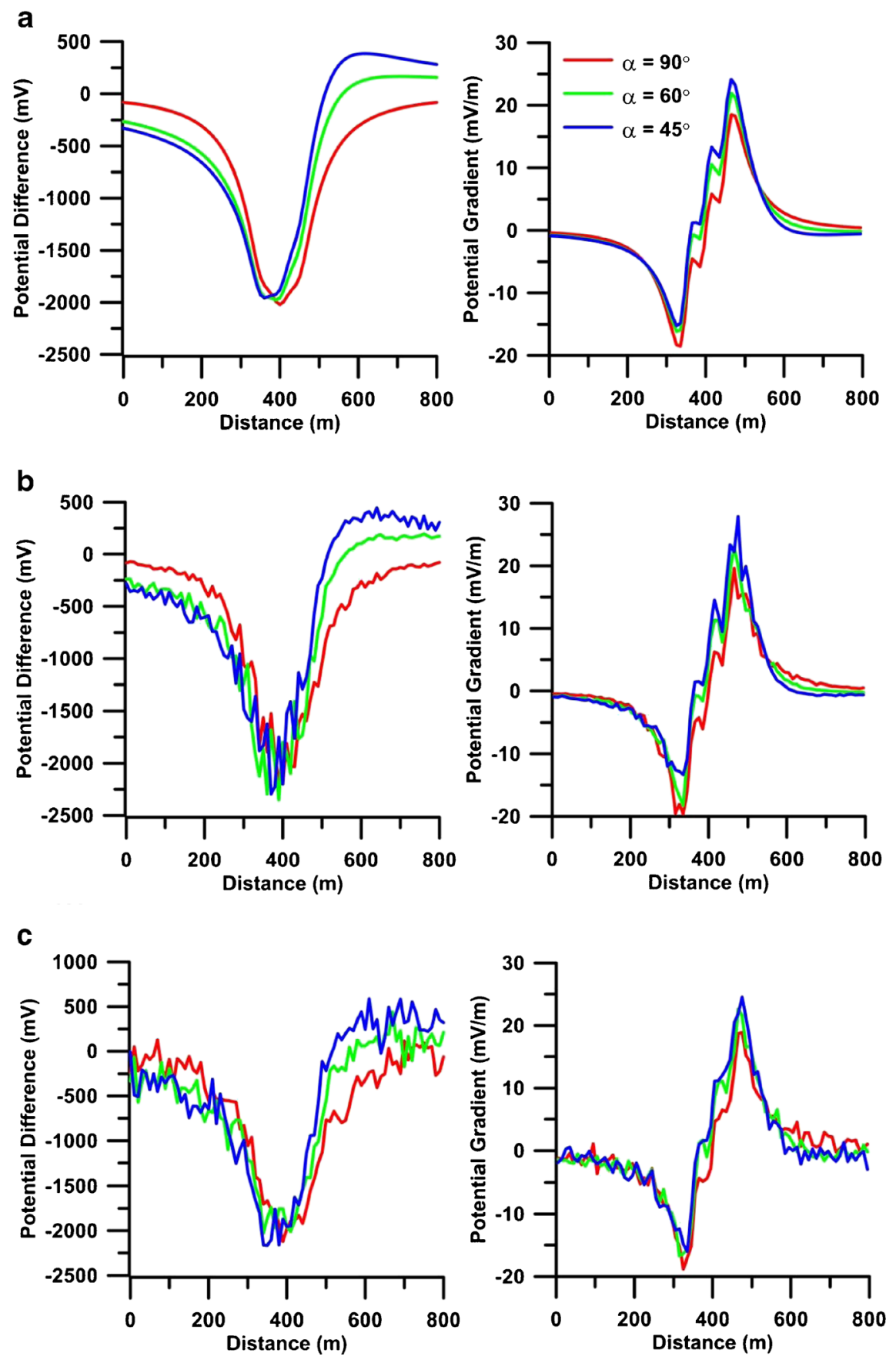

Figure 5. Potential difference and potential gradient anomaly with varying $\alpha$ : (a) noise-free data; (b) $20 \%$ random noise data; and (c) $20 \%$ Gaussian noise data.

the top $\left(z_{1}\right)$ separation to resolve the multiple bodies. Also, when the separation between the bodies increases for $\mathrm{PD}$, the anomaly decreases significantly (figure 7a). However, when the data is associated with noise, $\mathrm{PD}$ cannot resolve the structure (figure $7 \mathrm{~b}$ and $\mathrm{c}$ ). This suggests that measurements of PD can be done when the multiple structures are largely separated from each other; however, PG can resolve the closely spaced multiple sheet-type structures equally well.

\subsubsection{Two targets at various depth and separation}

Forward model. From the above studies, we found that the depth to the top $\left(z_{1}\right)$ and the separation $(d)$ play an important role in resolving the targets. There exists a relationship for PD and PG anomaly to resolve the closely spaced structures. Next, we have chosen another model with varying depth to the top and separation between two bodies to test the above finding. 

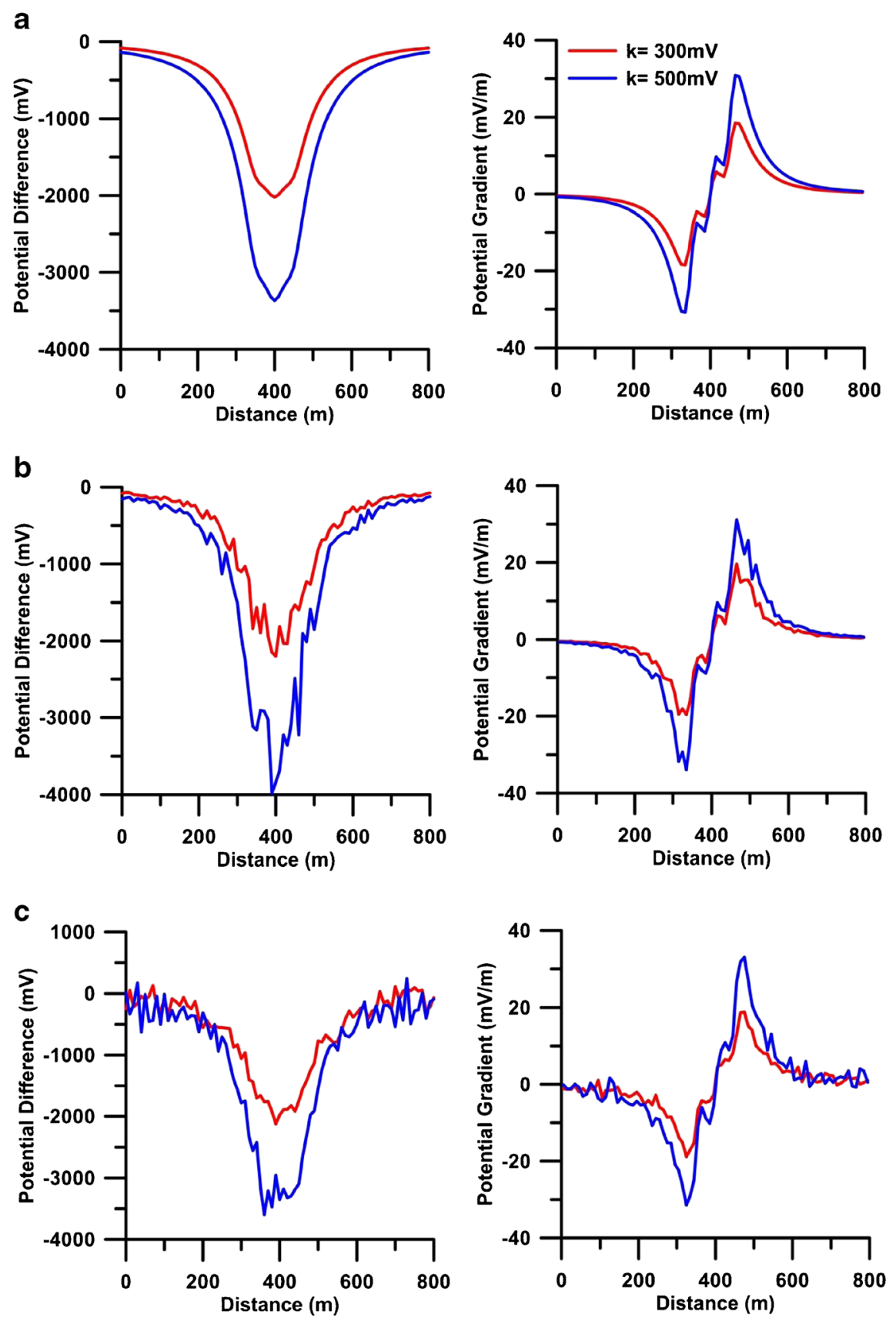

Figure 6. Potential difference and potential gradient anomaly with varying $k$ : (a) noise-free data; (b) $20 \%$ random noise data; and (c) 20\% Gaussian noise data.

Figure 8 depicts structures that are located with different depth and spacing, namely $25 \mathrm{~m}$ depth and $50 \mathrm{~m}$ spacing, $50 \mathrm{~m}$ depth with $100 \mathrm{~m}$ spacing, and $100 \mathrm{~m}$ depth with $200 \mathrm{~m}$ spacing. The polarization constant is $300 \mathrm{mV}$ and target length is $100 \mathrm{~m}$ in all cases. Table 2 depicts the model parameters.

The forward responses for PD and PG are computed and shown in figure $9.20 \%$ uniformly random noise and 20\% Gaussian noise is again added to the data to show the responses of data affected by noise. It reveals that PG can resolve the targets; however, $\mathrm{PD}$ cannot resolve the two bodies if $d<2 z_{1}$. Again, for $\mathrm{PD}$, if the data is associated with noise, it cannot reveal the exact number of structures from the anomaly itself. However, if the PG data is associated with noise, then also it can reveal the number of subsurface structures.

\section{Inversion result}

Next, the forward response of Model C from table 2 is considered as observed response and optimization is performed using VFSA global optimization. 

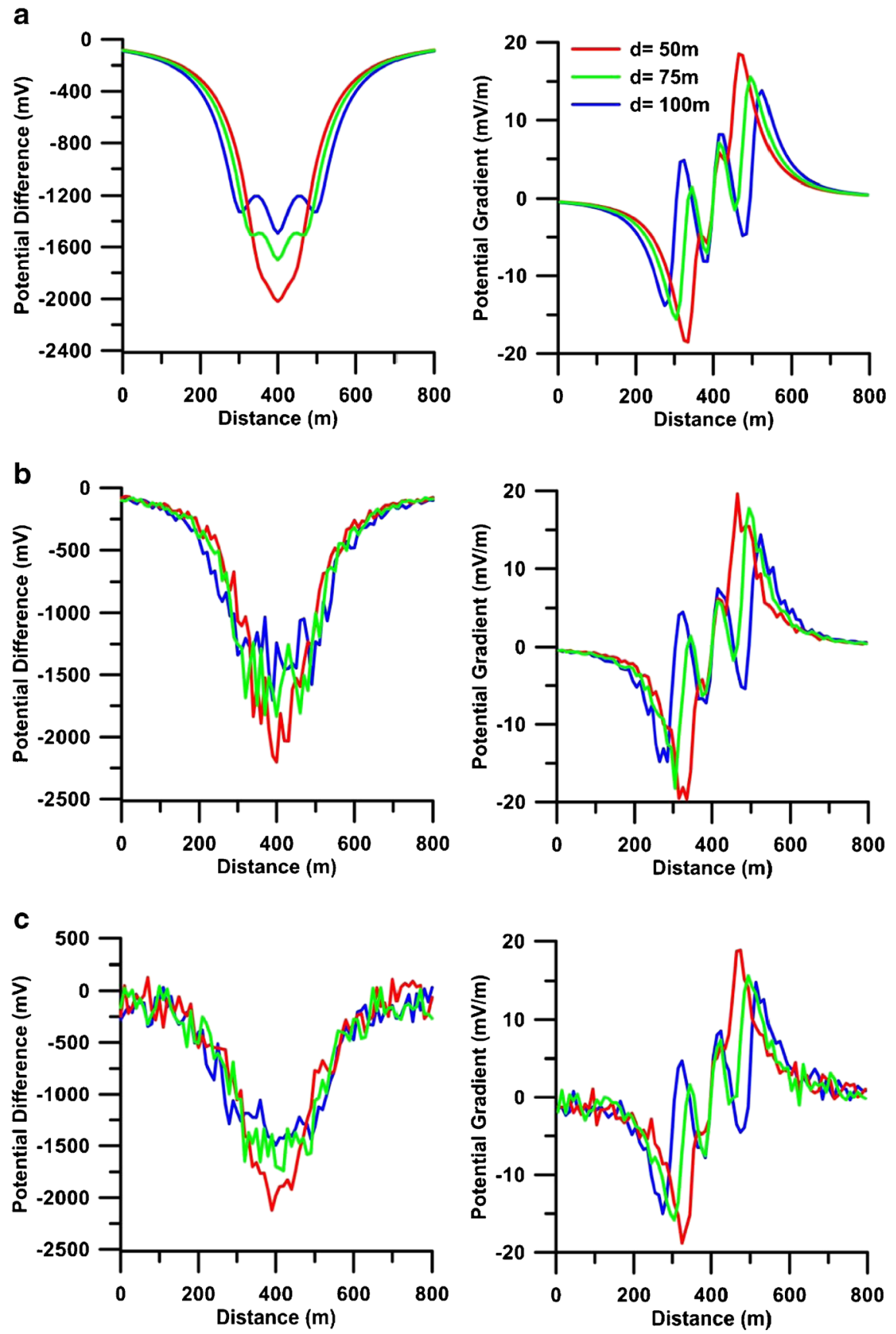

Figure 7. Potential difference and potential gradient anomaly with varying $d$ : (a) noise-free data; (b) $20 \%$ random noise data; and (c) $20 \%$ Gaussian noise data.

The search range for both $\mathrm{PD}$ and $\mathrm{PG}$ anomalies was kept same for inversion. The other parameters for VFSA inversion such as initial temperature, different temperature levels, number of moves per temperature and number of runs are same for both PG and PD.

After selecting a suitable search range for each model parameter, a single VFSA run is performed to check the appropriate convergence of each model parameter and misfit. Subsequently, 10 VFSA runs are performed and 10 solutions are derived. Since $10^{6}$ models are evaluated (2000 iterations $\times 50$ number of moves at each iteration $\times 10$ VFSA runs) whose misfits vary from $1-10^{-8}$ (noise-free synthetic data), therefore, models having misfit greater than $10^{-4}$ are discarded. The Gaussian PDF of all models whose misfit is less than $10^{-4}$ is computed. Finally, models for which each parameter is within one standard deviation of the PDF are selected to compute the statistical mean model and associated uncertainty.

Figure 10 shows the histogram and PDF for all parameters for $\mathrm{PD}$ and $\mathrm{PG}$. It can be seen that the histogram of $k$ in case of PD and PG shows a wide 


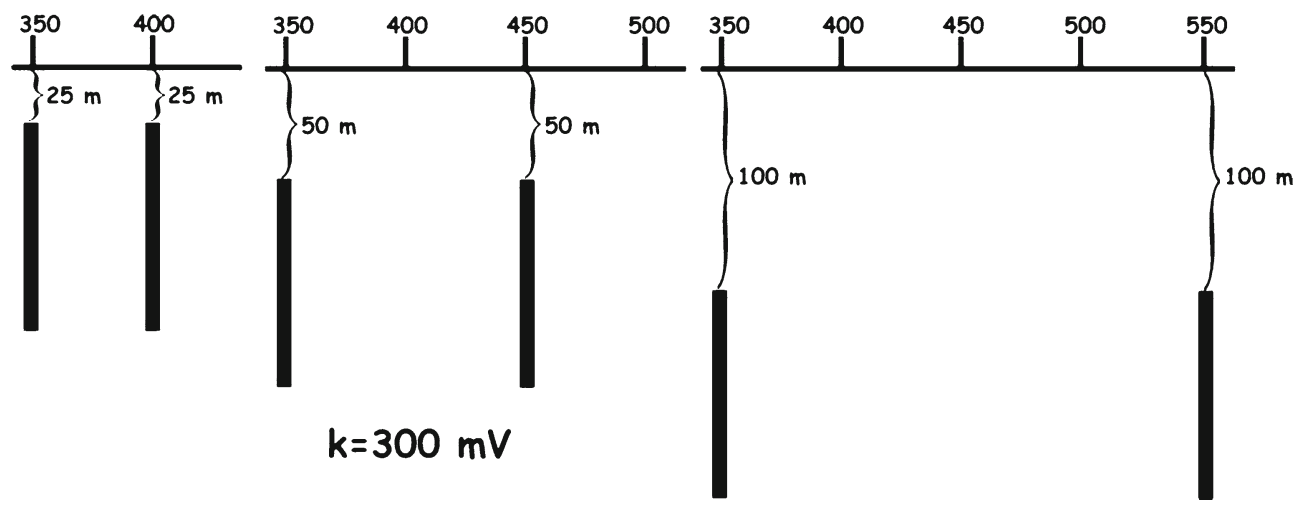

Figure 8. Sheet geometry for two closely spaced structures at different $z_{1}$ and $d$.

Table 2. Model parameters for three models at different depths and separations.

\begin{tabular}{|c|c|c|c|c|c|c|}
\hline \multirow[b]{2}{*}{ Parameters } & \multicolumn{2}{|c|}{ Model A } & \multicolumn{2}{|c|}{ Model B } & \multicolumn{2}{|c|}{ Model C } \\
\hline & $\mathrm{T} 1$ & $\mathrm{~T} 2$ & $\mathrm{~T} 1$ & $\mathrm{~T} 2$ & $\mathrm{~T} 1$ & $\mathrm{~T} 2$ \\
\hline$k(\mathrm{mV})$ & 300 & 300 & 300 & 300 & 300 & 300 \\
\hline$x_{1}(\mathrm{~m})$ & 350 & 400 & 350 & 450 & 350 & 550 \\
\hline$z_{1}(\mathrm{~m})$ & 25 & 25 & 50 & 50 & 100 & 100 \\
\hline$x_{2}(\mathrm{~m})$ & 350 & 400 & 350 & 450 & 350 & 550 \\
\hline$z_{2}(\mathrm{~m})$ & 125 & 125 & 150 & 150 & 200 & 200 \\
\hline
\end{tabular}

range of solutions for all accepted models; however, PDF computed from those models whose misfit is less than $10^{-4}$ shows that the peak anomaly is closer to the actual value. This is due to the combined effect of SP anomaly of multiple structures. The other parameters such as $x_{1}, z_{1}$, and $x_{2}$ show some consistency in delineating the actual model parameters. However, the resolution of finding the actual model parameter for PG is much better than PD. There is a well-defined peak for PG within limited range; however, $\mathrm{PD}$ shows a wide range. Histogram for $z_{2}$ for both PD and PG shows a wide range. However, resolution of $\mathrm{PG}$ is better than PD. Table 3 shows the various models' parameters obtained after inversion of PG and PD data. The optimized results obtained are in good agreement with the initial synthetic models and the fitting between observed and model data is shown in figure 11(a). However, the misfit obtained from inversion of $\mathrm{PG}$ data is smaller than $\mathrm{PD}$. This is due to the fact that PG can resolve multiple structures, whereas PD results show some uncertainty.

Since the nature of noise in actual field data is unknown, the inversion results for different kinds of noise are worth investigating. Next, we added $20 \%$ uniformly random noise and 20\% Gaussian noise to the data to show the efficacy of the inversion results for noisy data. A suitable search range is again selected for each model parameter and a single VFSA run is performed to check the appropriate convergence of each model parameter and misfit. Here, the search ranges were kept same for noise free and noisy data for continuity. Again, 10 VFSA runs are performed and 10 solutions are derived. Since $10^{6}$ models are again evaluated whose misfits vary from $2-10^{-2}$ (20\% random and Gaussian noisy data); therefore, models having misfit less than 0.02 are selected for statistical analysis. Finally, models for which each parameter is within one standard deviation of the PDF are selected to compute the statistical mean model and associated uncertainty. For brevity, we do not show the histogram for noisy data as it is similar to figure 10 for noise-free synthetic data.

Tables 4 and 5 show the various models' parameters obtained after inversion of PG and PD data for $20 \%$ uniformly random noise and $20 \%$ Gaussian noise. The optimized results obtained are in good agreement with the initial synthetic models and the fitting between observed and model data are shown in figure 11(b) (20\% uniformly random noise) and 11(c) (20\% Gaussian noise). In noisy data, the misfit obtained from inversion of $P G$ data is again smaller than PD data.

\subsection{Field example}

The field data have been measured at Beldih mine (figure 12), South Purulia Shear Zone (SPSZ) where uranium mineralization has been reported (Katti et al. 2010). Beldih mine area consists of ultramafic rocks, quartz-magnetite-apatite, carbonatite, metabasics, tuffaceous phylite, chloritemica schist, quartzite and alkali granite rocks (Gupta and Basu 2000; Acharyya et al. 2006; Vapnik et al. 2007; Sen et al. 2010) (figure 12). The shear zone shows ductile to brittle-ductile nature (Acharyya et al. 2006) associated with intense brecciation, mylonitization and hydrothermal alterations due to which the area becomes highly inhomogeneous. The general trend of the foliation along the shear zone is E-W to ESE-WNW with steep dip due north or south or vertical at places (Katti et al. 2010). The ferruginous kaolinite and 

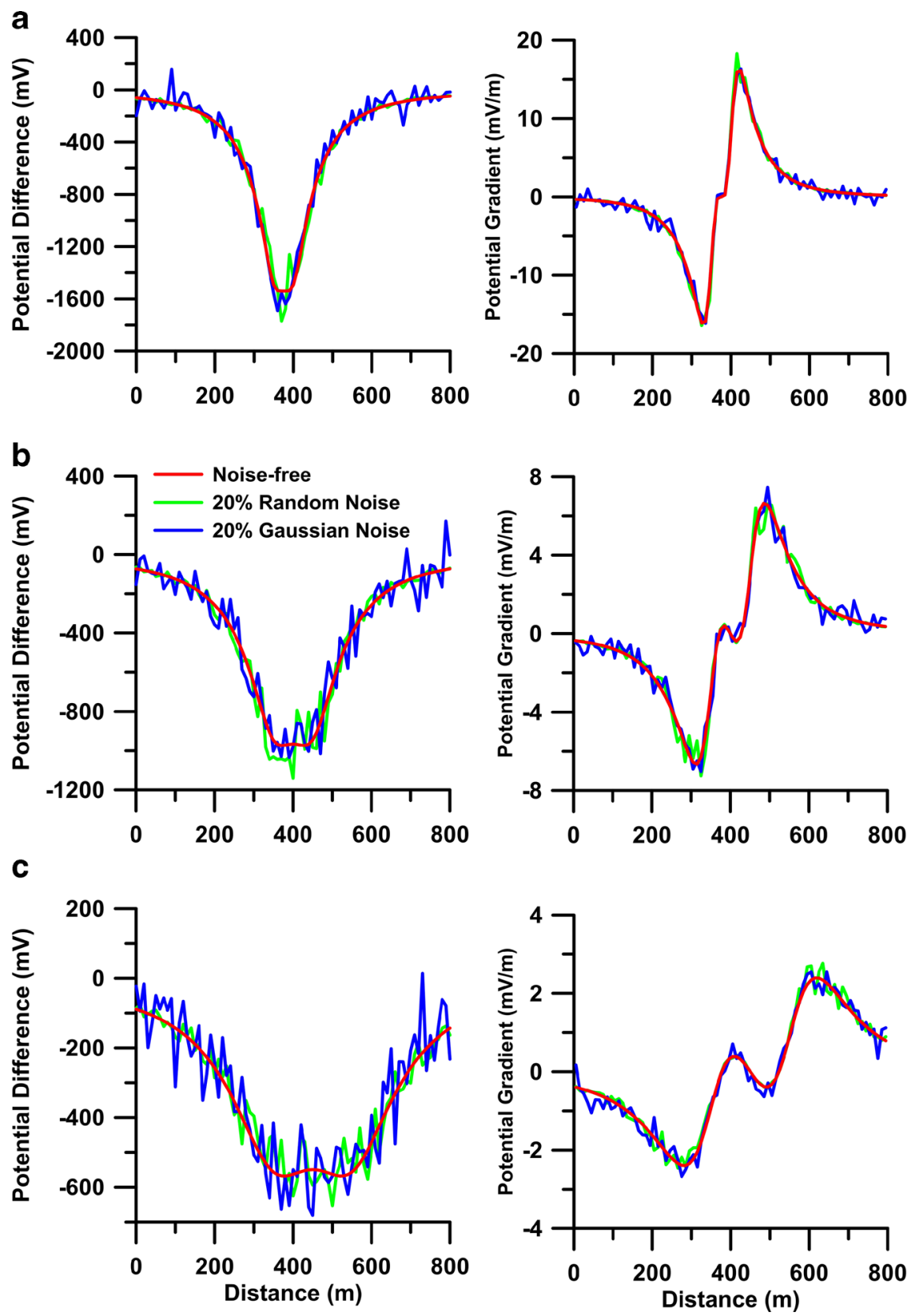

Figure 9. Potential difference and potential gradient anomaly with varying $z_{1}$ and $d:(\mathbf{a}) z_{1}=25 \mathrm{~m}, d=50 \mathrm{~m}$; (b) $z_{1}=50 \mathrm{~m}, d=100 \mathrm{~m}$; and (c) $z_{1}=100 \mathrm{~m}, d=200 \mathrm{~m}$.

quartz-magnetite-apatite rocks at Beldih mine are the main units for uranium mineralization (Katti et al. 2010; Sen et al. 2010).

The PD and PG measurements have been performed on the same profile to see whether there is any difference in the resolution for different subsurface structures (figure 13a and c). The data were acquired at $10 \mathrm{~m}$ interval. A Gradient Resistivity Profiling (GRP) measurement along the same profile (figure 13e) was also performed to check whether those SP anomalies associated with different structures can also be validated with resistivity measurement.
The PD anomaly shown in figure 13(a) depicts three sheet-type structures. However, the observed data is almost flat after three structures. Optimizing multiple sheets to fit the whole PD data leads to erroneous results. Therefore, only three targets were considered for optimization. The model data for interpreted model matched well with the observed data (figure 13a). A vertical cross-section of multiple structures with their orientation, negative and positive poles and polarization constants are shown in figure 13(b).

Figure 13(c) shows that the PG anomaly depicts five sheet-type structures. Model parameters were 

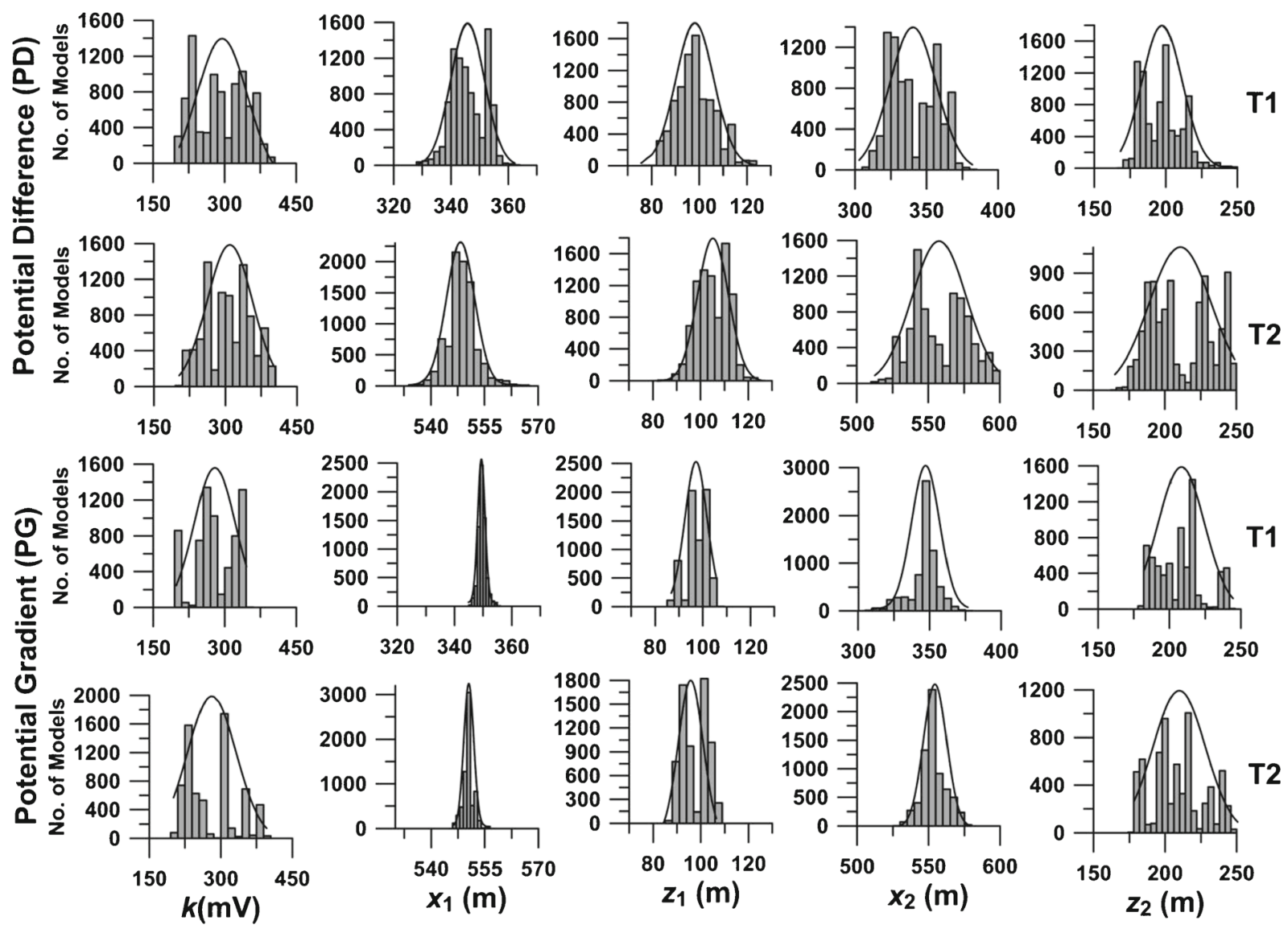

Figure 10. Histogram and PDF of accepted models with misfit lower than 0.0001 from potential difference and potential gradient anomaly.

Table 3. Interpreted model parameters for PD and PG with misfits for Model C (noise-free data).

\begin{tabular}{|c|c|c|c|c|c|c|c|c|}
\hline \multirow[b]{2}{*}{ Parameters } & \multicolumn{2}{|c|}{ Model C } & \multicolumn{2}{|c|}{ Search range } & \multicolumn{2}{|c|}{$\mathrm{PD}$} & \multicolumn{2}{|c|}{ PG } \\
\hline & $\mathrm{T} 1$ & $\mathrm{~T} 2$ & $\mathrm{~T} 1$ & $\mathrm{~T} 2$ & $\mathrm{~T} 1$ & $\mathrm{~T} 2$ & T1 & $\mathrm{T} 2$ \\
\hline$k(\mathrm{mV})$ & 300 & 300 & $200-400$ & $200-400$ & $307.7 \pm 24.7$ & $330.4 \pm 17.8$ & $270.6 \pm 19.9$ & $283.9 \pm 25.4$ \\
\hline$x_{1}(\mathrm{~m})$ & 350 & 550 & $300-400$ & $500-600$ & $347.5 \pm 2.7$ & $546.4 \pm 2.0$ & $349.9 \pm 0.5$ & $550.3 \pm 0.4$ \\
\hline$z_{1}(\mathrm{~m})$ & 100 & 100 & $50-150$ & $50-150$ & $97.4 \pm 1.3$ & $105.5 \pm 2.0$ & $96.9 \pm 2.1$ & $98.2 \pm 2.7$ \\
\hline$x_{2}(\mathrm{~m})$ & 350 & 550 & $300-400$ & $500-600$ & $349.7 \pm 10.0$ & $547.2 \pm 11.2$ & $348.1 \pm 2.6$ & $551.4 \pm 2.4$ \\
\hline$z_{2}(\mathrm{~m})$ & 200 & 200 & $150-250$ & $150-250$ & $186.9 \pm 3.9$ & $204.4 \pm 9.5$ & $209.9 \pm 6.8$ & $204.6 \pm 8.2$ \\
\hline Misfit & & & & & \multicolumn{2}{|c|}{$1.1 \times 10^{-5}$} & \multicolumn{2}{|c|}{$8.5 \times 10^{-6}$} \\
\hline
\end{tabular}

optimized in a similar way as discussed above. The model data matched very well with the observed data (figure 13c). A vertical cross-section of the multiple structures for PG is shown in figure 13(d) with the orientation, negative and positive poles, and polarization constants of various targets.

Here, we would like to emphasize that the nature of the PD and PG is different (figure 13a and c). $\mathrm{PD}$ suggests the presence of three conductive features whereas, PG suggests five conductive features. PG can resolve multiple small structures equally well, however, PD failed to do so. Even though the magnitude is very small, this is a typical characteristic of SP associated with mineralization. The apparent resistivity measured along the same profile using GRP array is correlated very well with the PG anomaly. The anomaly between -25 and $0 \mathrm{~m}$ location is associated with uranium mineralization (Katti et al. 2010).

The bore-hole (BLD-2 and 3) from Beldih mine (figure 12 inset) shows that the structures are almost vertical to slightly dipping $\left(86^{\circ}\right)$ towards south. However, in the present area, the structures are almost vertical or dipping due north and south as mentioned earlier (Katti et al. 2010). The dip of the structures changes abruptly within every few 

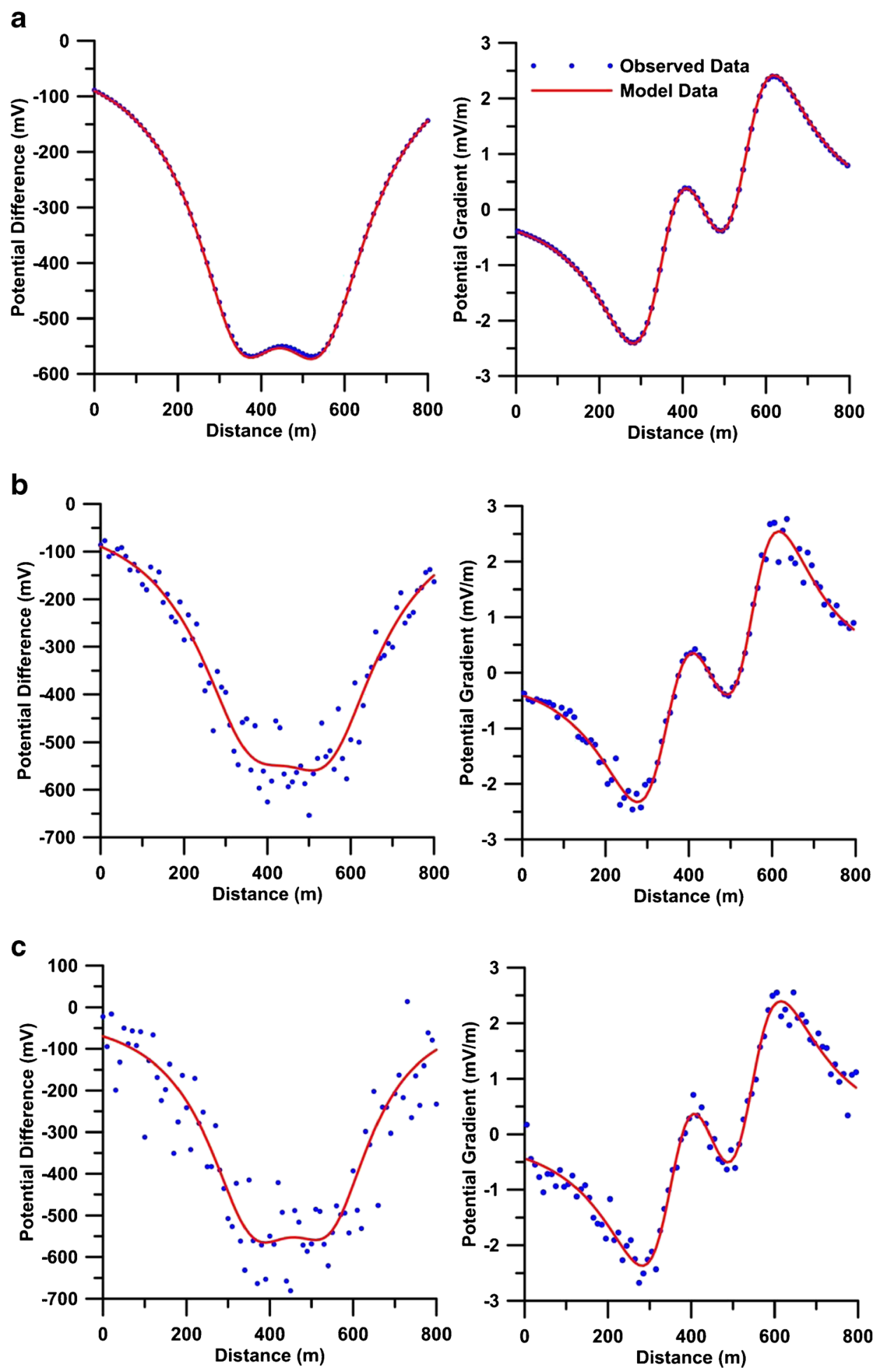

Figure 11. Fittings between the observed (solid dots-blue) and model response (solid line-red) of potential difference and potential gradient anomaly with varying $z_{1}$ and $d$ for Model C: (a) $z_{1}=25 \mathrm{~m}, d=50 \mathrm{~m} ;(\mathbf{b}) z_{1}=50 \mathrm{~m}, d=100 \mathrm{~m}$; (c) $z_{1}=100 \mathrm{~m}, d=200 \mathrm{~m}$.

meters. Three structures in PD and five structures in PG show that all are dipping towards north. The first, second and third structures in PD dip $46^{\circ}, 71^{\circ}$ and $71^{\circ}$ towards north. In PG, the first structure is almost horizontal ( $3^{\circ}$ towards north). The second structure which is the main anomaly zone associated with mineralization dips $71^{\circ}$ towards north. The third, fourth and fifth structures dip $49^{\circ}$, $69^{\circ}$ and $60^{\circ}$, respectively. The second structure in both PD and PG anomalies are associated with 
Table 4. Interpreted model parameters for PD and PG with misfits for Model C (20\% random noise data).

\begin{tabular}{|c|c|c|c|c|c|c|c|c|}
\hline \multirow[b]{2}{*}{ Parameters } & \multicolumn{2}{|c|}{ Model C } & \multicolumn{2}{|c|}{ Search range } & \multicolumn{2}{|c|}{$\mathrm{PD}$} & \multicolumn{2}{|c|}{ PG } \\
\hline & $\mathrm{T} 1$ & $\mathrm{~T} 2$ & $\mathrm{~T} 1$ & $\mathrm{~T} 2$ & $\mathrm{~T} 1$ & $\mathrm{~T} 2$ & $\mathrm{~T} 1$ & $\mathrm{~T} 2$ \\
\hline$k(\mathrm{mV})$ & 300 & 300 & $200-400$ & $200-400$ & $289.2 \pm 27.5$ & $282.7 \pm 29.8$ & $297.2 \pm 22.2$ & $258.5 \pm 33.4$ \\
\hline$x_{1}(\mathrm{~m})$ & 350 & 550 & $300-400$ & $500-600$ & $353.0 \pm 8.5$ & $548.0 \pm 8.4$ & $348.2 \pm 1.3$ & $550.7 \pm 0.8$ \\
\hline$z_{1}(\mathrm{~m})$ & 100 & 100 & 50-150 & 50-150 & $116.1 \pm 9.1$ & $111.2 \pm 9.1$ & $103.7 \pm 2.3$ & $92.3 \pm 4.2$ \\
\hline$x_{2}(\mathrm{~m})$ & 350 & 550 & $300-400$ & $500-600$ & $343.5 \pm 13.2$ & $556.8 \pm 15.0$ & $345.9 \pm 5.7$ & $559.4 \pm 8.3$ \\
\hline$z_{2}(\mathrm{~m})$ & 200 & 200 & $150-250$ & $150-250$ & $215.8 \pm 12.6$ & $219.7 \pm 11.5$ & $208.9 \pm 7.3$ & $205.0 \pm 14.0$ \\
\hline Misfit & & & & & 3.6 & $0^{-3}$ & 1.2 & \\
\hline
\end{tabular}

Table 5. Interpreted model parameters for PD and PG with misfits for Model C (20\% Gaussian noise data).

\begin{tabular}{|c|c|c|c|c|c|c|c|c|}
\hline \multirow[b]{2}{*}{ Parameters } & \multicolumn{2}{|c|}{ Model C } & \multicolumn{2}{|c|}{ Search range } & \multicolumn{2}{|c|}{$\mathrm{PD}$} & \multicolumn{2}{|c|}{ PG } \\
\hline & $\mathrm{T} 1$ & $\mathrm{~T} 2$ & $\mathrm{~T} 1$ & $\mathrm{~T} 2$ & $\mathrm{~T} 1$ & $\mathrm{~T} 2$ & T1 & $\mathrm{T} 2$ \\
\hline$k(\mathrm{mV})$ & 300 & 300 & $200-400$ & $200-400$ & $277.5 \pm 29.3$ & $270.2 \pm 29.7$ & $282.6 \pm 18.7$ & $304.8 \pm 24.5$ \\
\hline$x_{1}(\mathrm{~m})$ & 350 & 550 & $300-400$ & $500-600$ & $353.4 \pm 7.2$ & $549.4 \pm 8.6$ & $353.9 \pm 1.2$ & $542.5 \pm 1.3$ \\
\hline$z_{1}(\mathrm{~m})$ & 100 & 100 & 50-150 & $50-150$ & $98.8 \pm 8.8$ & $91.9 \pm 9.4$ & $98.0 \pm 2.0$ & $98.6 \pm 2.3$ \\
\hline$x_{2}(\mathrm{~m})$ & 350 & 550 & $300-400$ & $500-600$ & $328.8 \pm 12.4$ & $575.5 \pm 13.5$ & $379.6 \pm 6.8$ & $514.4 \pm 6.9$ \\
\hline$z_{2}(\mathrm{~m})$ & 200 & 200 & $150-250$ & $150-250$ & $200.9 \pm 11.4$ & $179.2 \pm 13.6$ & $220.4 \pm 11.3$ & $205.7 \pm 12.2$ \\
\hline Misfit & & & & & 1.4 & $10^{-2}$ & 3.5 & $0^{-3}$ \\
\hline
\end{tabular}

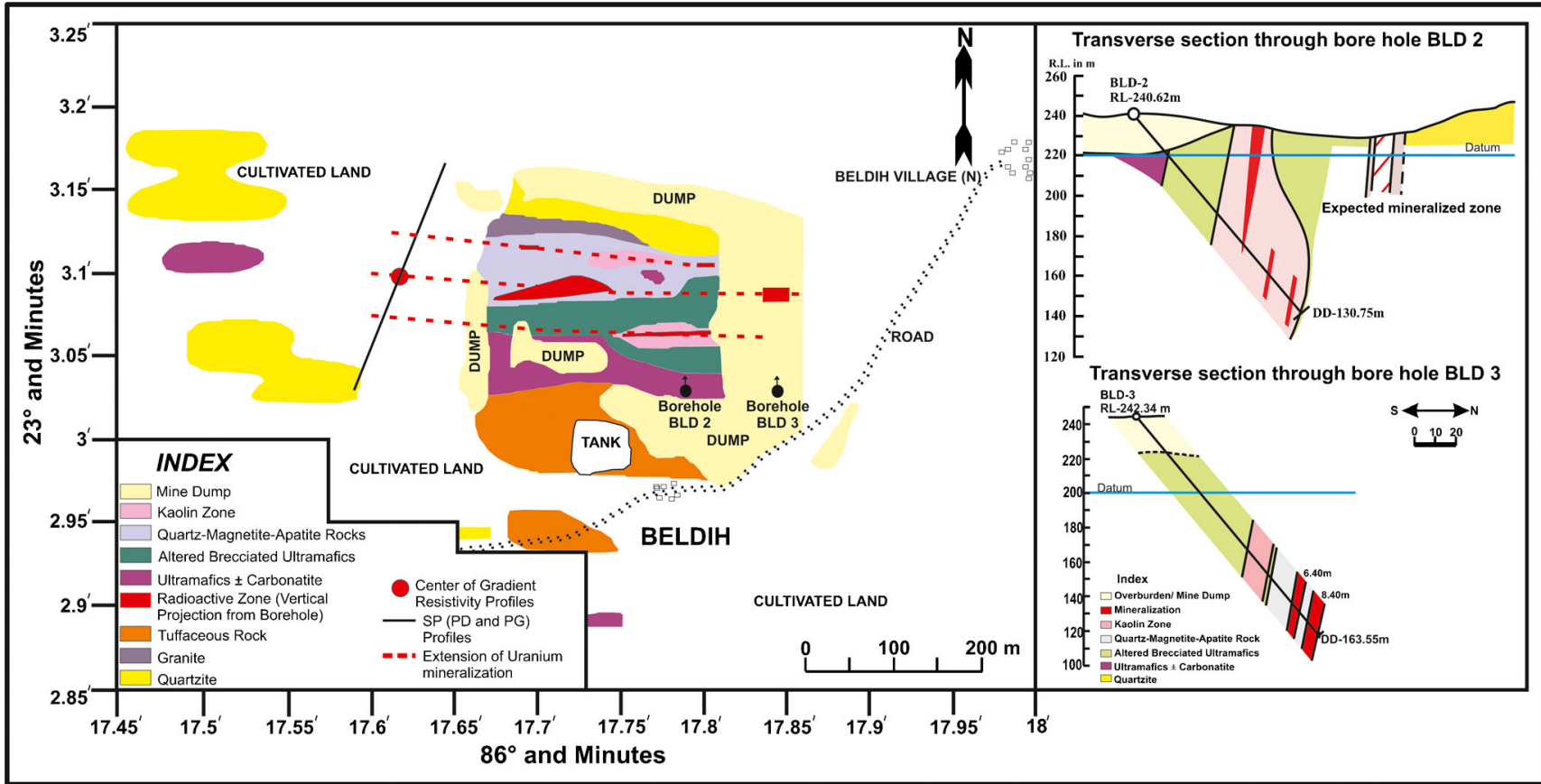

Figure 12. Geological map of Beldih mine, SPSZ (modified after Katti et al. 2010) with gradient resistivity profiling and SP (PD and PG) measurements. Transverse section through bore-hole BLD 2 and BLD3, Beldih area (after Katti et al. 2010) is shown in the inset.

mineralization as the signature of presence of mineralization can be very well seen from the figure 12 (inset). However, the structure interpreted from the $\mathrm{PG}$ anomaly is more realistic as it goes upto a depth of around $80 \mathrm{~m}$ from the surface whereas in PD anomaly it shows a very small structure. This is also evident from the borehole drilled at another location east of bore-hole (BLD 3) where uranium mineralization had been found near the surface and goes upto a depth of around $70 \mathrm{~m}$ from surface (figure 12 inset BLD 2 ). The third structure in PG and PD can also be 
a

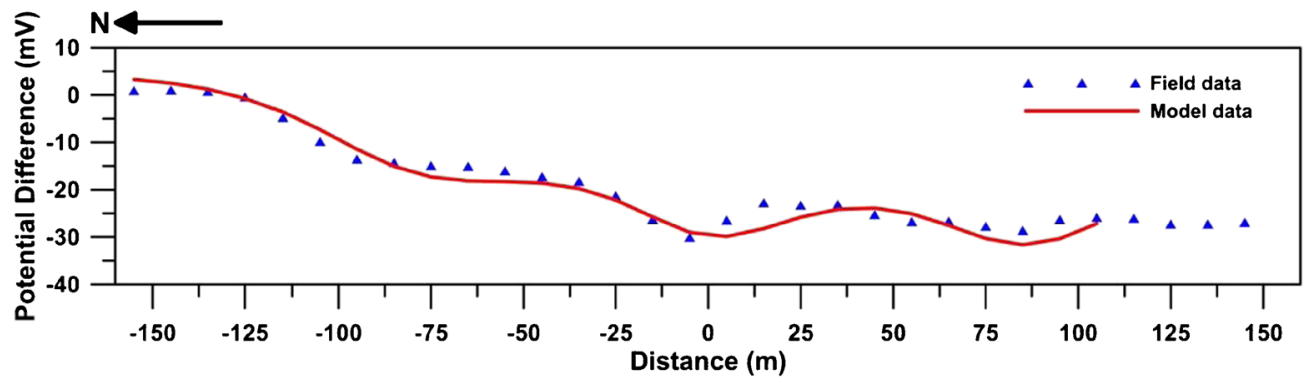

b

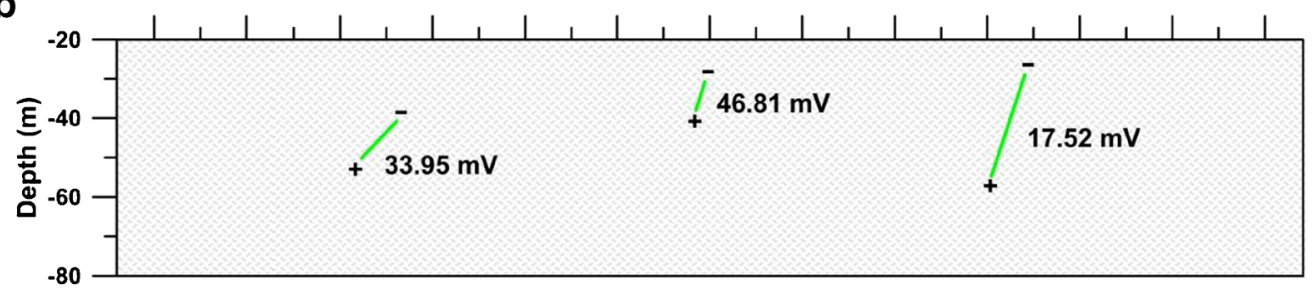

C

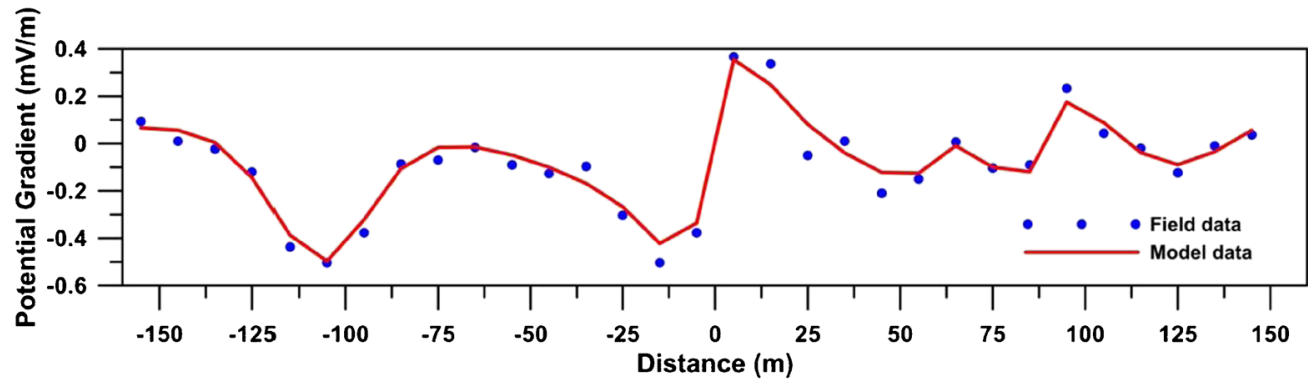

d

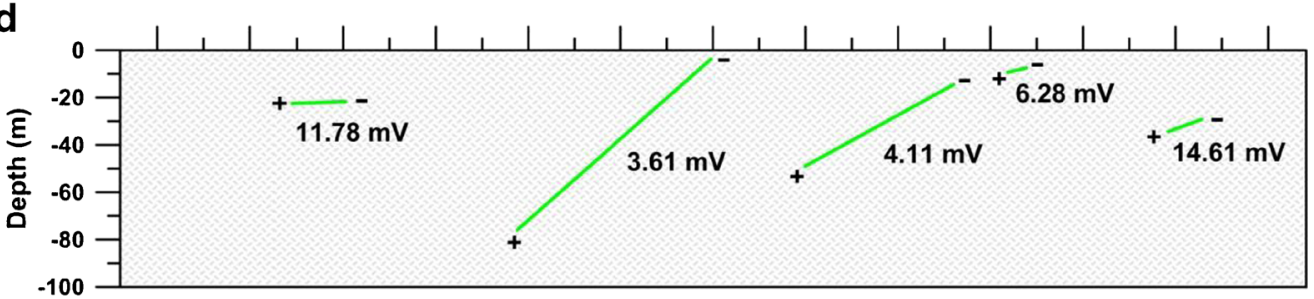

e

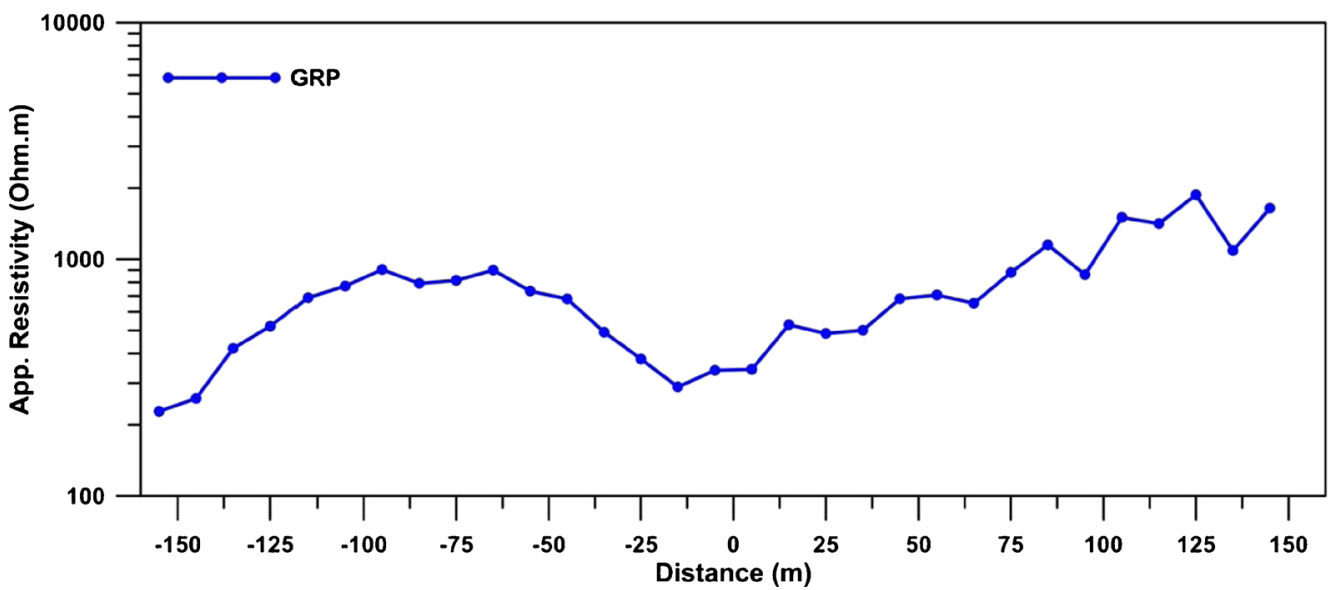

Figure 13. Field data from Beldih mine, SPSZ: (a) Fittings between field data (solid triangle-blue) and model response (solid line-red) of PD anomaly; (b) subsurface structure interpreted from PD anomaly; (c) fittings between field data (solid dots-blue) and model response (solid line-red) of PG anomaly; (d) subsurface structure interpreted from PG anomaly; and (e) GRP measurement along the same profile. 
correlated with the presence of uranium mineralization with the bore-hole data (BLD 2). Both structures extend up to a depth of around $55 \mathrm{~m}$ which is again closer to the mineralized band present in the drilled bore-hole. However, both structures dip opposite to the mineralization band present in the bore-hole. This might be because of high inhomogeneity in the subsurface but the radioactive bands extend in the western side of the mine. The other two structures (fourth and fifth) seen in PG anomaly are very small in size and could be associated with very small sources.

\section{Conclusions}

The resolution of self-potential anomalies due to closely spaced multiple sheet-like bodies by the potential difference and potential gradient was studied. It has been observed that the PG measurement is better in resolving multiple structures than PD measurement. It has also been observed that depth to the top $(z)$ and separation between two targets $(d)$ play an important role in the resolution of the parameters. If we consider three vertical sheets at depth $z$ and lying $2 z$ apart, it cannot be resolved using $\mathrm{PD}$ measurement but the same can be resolved very precisely using PG data. The resolution of parameters using $\mathrm{PD}$ data becomes more difficult when structures are dipping, however, PG data can resolve dipping structure equally well like vertical structure. The PD measurement requires a minimum separation of $4 z$ to resolve the vertical or dipping sheet-type structure. If the separation is less than $2 z$ then neither PG nor PD anomaly could resolve the structure. The efficacy of PG data in the inversion is demonstrated in the present study using noise-free synthetic data, noisy and field data. Interpreted results obtained by potential gradient measurement are in agreement with the bore-hole data.

\section{Acknowledgements}

Authors would like to express their sincere thanks to Dr A K Chaubey (Associate Editor) and two anonymous reviewers for their comments and suggestions that have improved the manuscript. $\mathrm{AB}$ thanks IIT Kharagpur for Institute research fellowship.

\section{References}

Acharyya A, Ray S, Chaudhuri B K, Basu S K, Bhaduri S K and Sanyal A K 2006 Proterozoic rock suites along South Purulia Shear Zone, eastern India: Evidence for rift-related setting; J. Geol. Soc. India 68 1069-1086.
Bhattacharya B B, Shalivahan and Sen M K 2003 Use of VFSA for resolution, sensitivity and uncertainty analysis in 1D-DC resistivity and IP inversion; Geophys. Prospect. $51393-408$.

Gupta A and Basu A 2000 North Singhbhum Proterozoic mobile belt, eastern India - a review; Geol. Surv. India Spec. Publ. 55 195-226.

Ingber L and Rosen B 1992 Genetic algorithms and very fast simulated re-annealing - A comparison; Mathematical and Computer Modeling 16 87-100.

Katti V J, Sen J and Bhatt A K 2010 Uranium potentiality of South Purulia Shear Zone in eastern Indian shield, Technical Meeting on Low Grade Uranium Ore, 29-31 March 2010, International Atomic Energy Agency (IAEA), Vienna, Austria.

Li J H, Feng D S, Xiao J P and Peng L X 2011 Calculation of all-time apparent resistivity of large loop transient electromagnetic method with very fast simulated annealing; J. Central South Univ. Technol. 18 1235-1239.

Mendonca C A 2008 Forward and inverse self-potential modeling in mineral exploration; Geophysics 73 F33-43.

Monteiro Santos F A, Almeida E P, Castro R, Nolasco M and Mendes-Victor L 2002 A hydrogeological investigation using EM34 and SP surveys; Earth Planet Space $\mathbf{5 4}$ $655-662$.

Murthy B V S and Haricharan P 1985 Nomograms for the complete interpretation of spontaneous potential profiles over sheet-like and cylindrical 2D structures; Geophysics 50 1127-1135.

Pei D H, Quirein J A, Cornish B E, Quinn D and Warpinski N R 2009 Velocity calibration of microseismic monitoring: A very vast simulated annealing (VFSA) approach for joint-objective optimization; Geophysics $\mathbf{7 4}$ 47-55.

Ramazi H, Nejad M R H and Firoozi A A 2009 Application of integrated geoelectrical methods in Khenadarreh (Arak, Iran) Graphite deposit exploration; J. Geol. Soc. India 74 260-266.

Sen M K and Stoffa P L 1995 Global Optimization Methods in Geophysical Inversion; 1st edn, Elsevier Publishers, Netherlands.

Sen J, Choudhury D K, Bhatt A K, Mahendra Kumar K and Parihar P S 2010 A preliminary note on uranium mineralization in South Purulia Shear Zone from Beldih area, Purulia District, West Bengal; In: Geology, Genesis, and Resource Analysis of Metallic, Non-Metallic and Energy Minerals (Coal, Petroleum \& Atomic Minerals) (ed.) Shekhawat M S, National Seminar, Abstract, pp. 226-227.

Sharma S P and Kaikkonen P 1998 Two-dimensional nonlinear inversion of VLF-R data using simulated annealing; Geophys. J. Int. 133 649-668.

Sharma S P and Kaikkonen P 1999 Appraisal of equivalence and suppression problems in 1-D EM and DC measurements using global optimization and joint inversion; Geophys. Prospect. 47 219-249.

Sharma S P 2012 VFSARES - A very fast simulated annealing FORTRAN program for interpretation of 1-D DC resistivity sounding data from various electrode array; Comput. Geosci. 42 177-188.

Sharma S P and Biswas A 2013 Interpretation of selfpotential anomaly over a $2 \mathrm{D}$ inclined structure using very fast simulated-annealing global optimization - An insight about ambiguity; Geophys. 78 WB3-15.

Srivastava R P and Sen M K 2009 Fractal-based stochastic inversion of poststack seismic data using very fast simulated annealing; J. Geophys. Eng. 6 412-425.

Sundararajan N, Srinivasa Rao P and Sunitha V 1998 An analytical method to interpret self-potential anomalies caused by 2D inclined sheets; Geophys. 63 1551-1555. 
Tarantola A 1987 Inverse Problem Theory, Methods of Data Fitting and Model Parameter Estimation; Elsevier Publishing Company, 630p.

Telford W M, Geldart L P and Sheriff R E 1990 Applied Geophysics; Cambridge University Press, 792p.

Vapnik Y, Bushmin S, Chattopadhyay A and DolivoDobrovolsky D 2007 Fluid inclusion and mineralogical study of vein-type apatite ores in shear zones from the Singhbhum metallogenetic province, West Bengal, India; Ore Geol. Rev. 32 412-430.

Zhao L S, Sen M K, Stoffa P and Frohlich C 1996 Application of very fast simulated annealing to the determination of the crustal structure beneath Tibet; Geophys. Prospect. 125 355-370. 